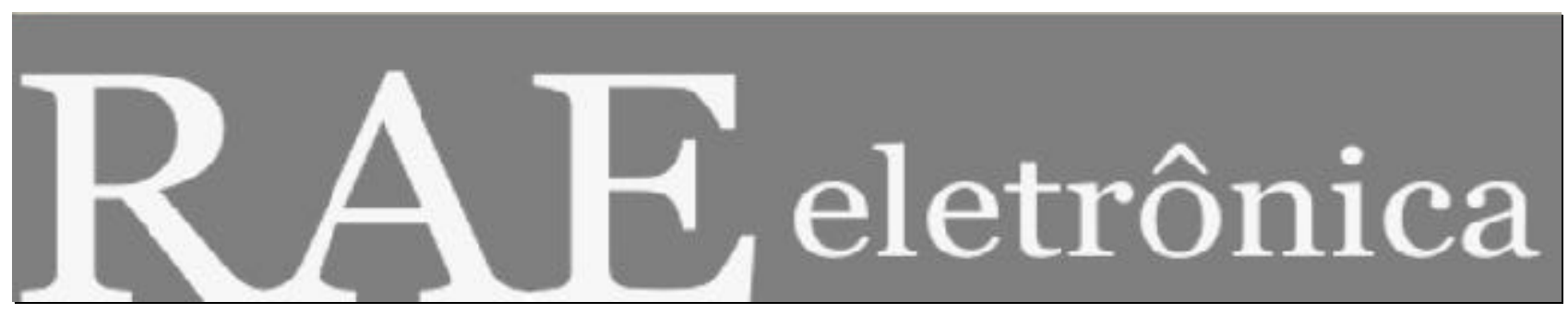

PROFETAS OU ILUSIONISTAS: A HISTÓRIA DOS GURUS DA ADMINISTRAÇÃO

Por:

Maurício Reinert do Nascimento

RAE-eletrônica, v. 3, n. 2, Resenha 3, jul./dez. 2004

http://www.rae.com.br/eletronica/index.cfm?FuseAction=Artigo\&ID=2289\&Secao=RESENHAS \&Vol ume $=3 \&$ Numero $=2 \&$ Ano $=2004$

CCopyright, 2004, RAE-eletrônica. Todos os direitos, inclusive de tradução, são reservados. É permitido citar parte de artigos sem autorização prévia desde que seja identificada a fonte. A reprodução total de artigos é proibida. Os artigos só devem ser usados para uso pessoal e nãocomercial. Em caso de dúvidas, consulte a redação: redacao@ rae.com.br.

A RAE-eletrônica é a revista on-line da FGV-EAESP, totalmente aberta e criada com o objetivo de agilizar a veiculação de trabalhos inéditos. Lançada em janeiro de 2002, com perfil acadêmico, é dedicada a professores, pesquisadores e estudantes. Para mais informações consulte o site www.rae.com.br/eletronica.

RAE-eletrônica

ISSN 1676-5648

(C2004 Fundação Getulio Vargas - Escola de Administração de Empresas de São Paulo.

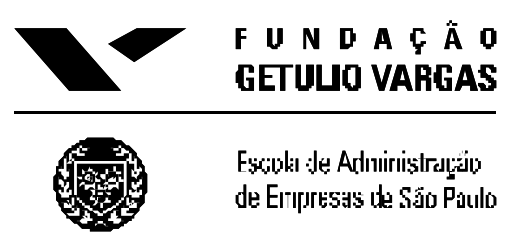




\section{PROFETAS OU ILUSIONISTAS: A HISTÓRIA DOS GURUS DA ADMINISTRAÇÃO}

Por:

\section{Maurício Reinert do Nascimento}

Professor do Curso de Administração das Faculdades Curitiba e Doutorando em Administração de empresas pela FGV-EAESP.

E-mail: $\underline{\text { m.reinert@uol.com.br }}$

\section{FALSE PROPHETS: THE GURUS WHO CREATED MODERN MANAGEMENT AND WHY THEIR IDEAS ARE BAD FOR BUSINESS TODAY}

De James Hoopes

Cambridge, MA: Perseus Publishing, 2003. 352 p.

"False Prophets" é mais que uma crítica aos gurus da administração e suas teorias, o tema central é o lugar do poder nessas teorias. Partindo da premissa de que o poder nas organizações é intrinsecamente de cima para baixo, e que é um dos responsáveis pelo sucesso das empresas americanas, o autor critica os gurus por não encararem sua existência nas empresas e, ao desenvolverem teorias procurando compatibilizar poder e democracia, mascararem a realidade e aprofundarem os problemas das relações autoritárias.

Apesar da sua importância, a discussão de poder não é a parte mais interessante do livro. O que fascina é a maneira como o autor escolheu para apresentar o tema, é isso que torna o livro leitura indispensável para professores e pesquisadores de Teoria das Organizações, e principalmente para executivos e empresários. Devido a sua formação de historiador, o autor mostra o contexto histórico-social do surgimento dos gurus, como suas teorias foram construídas, e quais os pressupostos por trás dessa construção. Por isso, o livro é mais dinâmico e interessante do que as abordagens tradicionais. Entre a importância e as limitações da discussão sobre poder, e a riqueza da imbricação histórico-social é que o livro se desenvolve.

Ao colocar o poder como tema central, o autor possui o mérito de trazer para a literatura gerencial um assunto costumeiramente deixado de lado. Ele discorre na introdução sobre a existência de uma contradição na sociedade americana entre o desejo de democracia e liberdade de expressão e a maneira autoritária como as organizações são administradas. Essa contradição causa embaraço às organizações e seus proprietários e gerentes, que por isso buscam escondê-la, e para isso contam com a ajuda de gurus e consultores. Hoopes se propõe a imunizar os leitores contra a arrogância moral inconsciente das idéias gerencias de hoje. Essa arrogância está na tentativa de apresentar modelos que resolvam a contradição entre sociedade democrática e empresa autoritária, considerando a primeira o modelo ideal e a segunda o mal a ser extirpado.

As propostas dos primeiros gurus, as quais impregnam as idéias gerencias de hoje, em vez de resolverem o problema apenas jogaram uma nuvem sobre a relação autoritária, o que acentua a contradição e a torna mais perversa. Para exemplificar esse argumento, o autor detalha a história de nove gurus da administração, mas antes descreve a sociedade americana escravocrata e o gerenciamento de or ganizações antes das teorias gerencias, fazendo uma sutil comparação com as atuais idéias da administração. Dois pontos são destaques. O primeiro é a busca, pelos senhores de 
escravos, de uma justificativa moral para escravidão, pois ela também contradizia aos valores de liberdade e democracia da sociedade. $\mathrm{O}$ autor compara essa busca com os modelos desenvolvidos pelos gurus, os quais teriam como objetivo encontrar a mesma justificativa. O segundo é a autonomia dada, no modelo escravocrata, aos capatazes responsáveis pelos os escravos. Autonomia essa utilizada também na forma de administrar as primeiras empresas. $\mathrm{O}$ autor sustenta que essa autonomia era responsável pela forma tirânica com que parte dos trabalhadores era tratada, pois por causa da falta de controle sobre suas ações, os capatazes acabavam por exceder-se no trato com os operários. Eles também pouco se preocupavam com os interesses dos proprietários da organização, visto que seus próprios interesses vinham primeiro lugar.

Apesar de importante, a discussão de poder tem seu ponto fraco. Ao tomar como interlocutores apenas a literatura americana gerencial, o autor ignora clássicos que trazem o tema do poder como fundamental para as organizações, como, por exemplo, Weber. Além disso, parte das premissas que as relações de poder nas organizações ocorrem sempre de cima para baixo e que é boa para a sociedade. Hoopes advoga que ela permite o sucesso das organizações modernas e como conseqüência a riqueza da economia, o conforto do consumo, o emprego e as demais facilidades da vida na sociedade americana. Quanto à primeira premissa, ela é bastante discutida nos meios acadêmicos, Hardy e Clegg no seu artigo no Handbook de Estudos Organizacionais fazem uma boa revisão sobre as diversas perspectivas de poder, de monstrando toda a complexidade do assunto. Diversas dessas perspectivas apresentam as características relacionais do poder, e como diferentes grupos adquirem e utilizam o poder no dia-a-dia da organização, independentemente de uma noção hierárquica. Sendo assim, a idéia de que poder se resume uma relação de autoridade é controversa. A segunda premissa, de que o poder é bom para a sociedade, também é questionável, seja pela análise das discussões da Teoria Crítica, seja pelo olhar para as diferenças entre as nações. É preciso ter consciência de que a relação de poder autoritária é parte das organizações, e ao insistir que ela deva ser discutida e compreendida, o autor acerta, agora aceitar que seus resultados são necessariamente bons para a sociedade parece ser uma visão limitada da realidade. O autor avalia somente a sociedade americana, e apenas no quesito geração de riqueza. As externalidades negativas que acompanham essa relação são ignoradas. Talvez esse tipo de relação de poder seja bom para a riqueza da organização, mas com certeza traz se não problemas, pelo menos desafios para a sociedade, os quais precisam ser discutidos e enfrentados, e não apenas aceitos, como pretende o autor. É o apego a essas duas premissas que prejudicam a discussão de poder.

No livro, os gurus foram divididos em três grupos: Administração Científica, Relações Humanas e Filosofia Social. No grupo da Administração Científica, o primeiro guru é Taylor, que é denominado de "O Demônio". Segundo Hoopes, o grande problema na teoria dele foi ter vendido a idéia de que a utilização do poder autoritário serve tanto a proprietários quanto a operários, pois eles estão do mesmo lado. Essa idéia foi comprada por muitos, e ainda hoje impregna o pensamento gerencial. De qualquer forma, a Administração Científica de Taylor aumentou a produtividade da industria americana, e ganhou seguidores. Outros três gurus desse grupo são apresentados. O casal Frank e Lílian Gilbreth e Henry Gantt deram continuidade aos trabalhos de Taylor, e foram responsáveis por deixar mais palatável aos olhos dos trabalhadores e da sociedade a Administração Científica. Apesar disso, a crise nessa Escola, em conjunto com o contexto histórico, trouxe a tona os gurus das Relações Humanas.

O segundo grupo inicia com Mary Parker Follet, a quem o autor chama de o mais equilibrado dos gurus do grupo. Para ele, Follet compreendeu a inevitabilidade do poder dentro das organizações e analisou suas limitações. Entretanto, idealizou a organização funcionando como uma comunidade, na qual o líder é também liderado, e vice-versa, e o poder autoritário é minimizado. O segundo guru é Elton Mayo, que é chamado de charlatão. Segundo o autor, Mayo deliberadamente omitiu dados da experiência de Hawthorne, e com isso pôde concluir o que desejava dos resultados. Subestimando a 
importância do poder e afirmando a possibilidade da criação de cooperação de baixo para cima por meio do gerenciamento de pessoas, ele acreditava na criação de uma comunidade dentro da empresa, na qual não existiria nenhum tipo de conflito de interesses, pensamento que casava muito bem com o ideal de liberdade e democracia. O último guru do grupo é Chester Barnard. Para o autor, Barnard sugere que não é preciso autoridade para gerenciar. A superioridade do gerente deve estar na sua liderança moral sobre os trabalhadores, pois essa gera cooperação. A partir da cooperação e do senso de responsabilidade dos trabalhadores é possível alcançar eficiência. Essa noção de autoridade moral persiste nos novos modismos da administração.

O grupo da Filosofia Social é composto por W. Edwards Deming e Peter Drucker. Apesar das diferenças teóricas, ambos chegam ao final de suas carreiras defendendo a administração como meio para o desenvolvimento de uma sociedade justa e democrática. Deming argumenta que o sucesso do TQM depende da participação do trabalhador, e que essa ferramenta foi responsável pelo sucesso das empresas japonesas no pós-guerra, e, em seguida pela retomada da liderança pelas empresas americanas, então é a participação democrática, e não o poder autoritário, o responsável pelo sucesso das organizações. Já Drucker admite a existência do poder, entretanto procura dar legitimidade moral a ele, afirmando que este deve ser usado para o bem dos empregados. Para ele, tornamo-nos a sociedade das organizações, e o gerenciamento eficiente delas é o melhor caminho para a resolução dos nossos problemas.

Os gurus, suas teorias e o papel do poder nas organizações já foram discutidos por diversos autores. A novidade desse livro está na maneira como o Hoopes constrói o contexto histórico-social em que os gurus estão envolvidos. Ele apresenta suas relações com outros personagens da época, instituições, organizações e acontecimentos históricos. Os fatos que os influenciaram são descritos com uma riqueza de detalhes, que o dia-a-dia das organizações em que atuaram passa a ser familiar. É essa imbricação social presente na obra de Hoopes, que é fundamental para a compreensão da prática da administração hoje nas organizações. 